\title{
Comparison of Ureaplasmas from Sheep and Goats with Ureaplasma diversum and $\boldsymbol{U}$. urealyticum
}

\author{
By C. J. HOW ARD* AND D. H. POCOCK \\ Agricultural Research Council, Institute for Research on Animal Diseases, Compton, Newbury, \\ Berkshire RG16 ONN, U.K.
}

(Received 31 March 1983; revised 9 May 1983)

Ureaplasmas isolated from sheep and goats were compared by immunofluorescence with antisera prepared in calves and by PAGE of polypeptides labelled by growth in the presence of $\left[{ }^{35}\right.$ S $]$ methionine. The ovine and caprine strains constituted two groups defined by serology and polypeptide composition that were not related to the animal species from which they originated. Strains representing these two groups were compared with Ureaplasma urealyticum (human isolates) and $U$. diversum (bovine isolates). They could not be classified with either but were more similar to the $U$. diversum strains.

\section{INTRODUCTION}

Ureaplasmas, mycoplasmas possessing urease, were initially isolated from man. Amongst human isolates a number of distinct serotypes exist which are at present included in a single species, Ureaplasma urealyticum (Shepard et al., 1974; Robertson \& Stemke, 1982). DNA homology studies (Christiansen et al., 1981) and comparisons of polypeptides by PAGE (Howard et al., 1981; Mouches et al., 1981) have indicated that strains representing these serotypes comprise two clusters.

Isolates from cattle, the second animal species from which ureaplasmas were isolated (TaylorRobinson et al., 1967) are also serologically heterogeneous. Studies in which rabbit antisera prepared against various strains were used in several tests, including metabolism inhibition, growth inhibition and immunofluorescence, indicated that bovine ureaplasmas existed as three clusters of similar, cross-reacting, but not identical strains (Howard et al., 1975, 1978 a; Ogata et al., 1979). These bovine isolates appeared serologically distinct from $U$. urealyticum, the human isolates, and have also been reported to be distinct from ureaplasmas isolated from dogs (Kotani \& Ogata, 1979), cats (Kotani et al., 1980a), sheep and goats (Kotani et al., 1980b) and nonhuman primates (Ogata et al., 1981), although it is possible that internal antigens common to the genus exist (Nagatomo et al., 1980; Stemke \& Robertson, 1981).

Isolates from cattle have also been shown to be distinct from strains representing $U$. urealyticum by comparing guanine + cytosine $(\mathrm{G}+\mathrm{C})$ content of DNA (Howard et al., 1974, 1978 b) and polypeptides by PAGE (Howard et al., 1981; Mouches et al., 1981), and it has been proposed that the bovine isolates should be considered as a second species of the genus Ureaplasma, U. diversum (Howard \& Gourlay, 1982).

Serological studies of ovine ureaplasmas by a complement-killing test utilizing rabbit antisera indicated a large number of serotypes (Livingston et al., 1978). Other studies with rabbit antisera employed in metabolism-inhibition and growth-inhibition tests resulted in ovine and caprine isolates being divided into two serological groups not related to the species of origin (Kotani et $a l ., 1980 \mathrm{~b}$ ), and distinct from human or bovine strains.

It has been suggested that, with bovine isolates, antisera produced in calves were less discriminating than rabbit antisera and that bovine strains fell into three serogroups (Howard \& Gourlay, 1981). Furthermore, the $G+C$ contents of DNA from ovine-caprine ureaplasmas 
were similar to those of bovine strains but distinct from the values found for human isolates (Howard et al., 1978b). The aim of this study was to compare certain ovine-caprine ureaplasmas with the bovine strains by serology, employing antisera produced in calves, and by analysis of polypeptides by PAGE to examine the relationship between ovine-caprine isolates and $U$. diversum and to determine whether the ovine-caprine isolates could be grouped in a similar manner to the bovine ones.

\section{METHODS}

Ureaplasma strains. The strains listed in Table 1 were grown in either $\mathrm{U} 4$ broth or solid medium as described previously (Howard \& Gourlay, 1981). All were cloned by picking single colonies at least three times after filtration (450 $\mathrm{nm}$ pore size; Millipore).

Serological tests. The immunofluorescence test was that of Rosendal \& Black (1972) with modifications as previously reported (Howard \& Gourlay, 1981). The titre of an antiserum was taken as the reciprocal of the highest dilution that produced fluorescence with fluorescein-coupled rabbit anti-bovine serum (Nordic Immunology) diluted $1 / 10$ in PBS $\left(0.15 \mathrm{M}-\mathrm{NaCl}, 0.01 \mathrm{M}-\mathrm{PO}_{4} ; \mathrm{pH} 7 \cdot 2\right)$. In some cases, agar-blocks with colonies were incubated under $1 \%(\mathrm{v} / \mathrm{v})$ Triton X-100 in PBS for $3 \mathrm{~min}$ at room temperature and washed three times with PBS before proceeding with the standard immunofluorescence test (Stemke \& Robertson, 1981).

For the metabolism inhibition test (Purcell et al., 1966) antisera were diluted in microtitre trays in $25 \mu$ l volumes of U4 broth. Broth containing $5 \%(\mathrm{v} / \mathrm{v})$ guinea pig serum $(50 \mu \mathrm{l})$ thawed once from a stock stored unheated at $-70^{\circ} \mathrm{C}$, was added to each well followed by dilutions $(25 \mu \mathrm{l})$ of the appropriate strain in broth. The titre of an antiserum was taken as the reciprocal of the highest dilution that inhibited an alkaline colour change, due to ureaplasma growth, after incubation overnight at $37^{\circ} \mathrm{C}$.

Antisera. Antisera were prepared in gnotobiotic calves (Howard \& Gourlay, 1981) against $U$. diversum strains A417, D48 and T44, representatives of the three groups within this species (Howard \& Gourlay, 1982), and against ovine strains Ov1202 and T515, selected on the basis of a preliminary examination of their polypeptides, which indicated that they were different. Antisera were also made in conventionally reared calves. These were against ureaplasma strain A417 (to check that gnotobiotic and conventionally reared animals reacted similarly) and ovine strain Ov624, which did not react with antisera to ovine strains Ov1202 or T515 in preliminary titrations. Antisera were also prepared in conventionally reared calves against $U$. urealyticum strains 7 and T960 (serotypes 1 and 8 ), chosen as representatives of the two clusters of strains evident within this species, and against Mycoplasma arginini (NCTC 10129), selected as a non-Ureaplasma species (control) that grew in U4 broth. Antibodies to these strains were not detected in pre-inoculation serum samples.

$P A G E$. Polypeptides were labelled by growing organisms in the presence of $\left[{ }^{35} \mathrm{~S}\right]$ methionine and analysed by SDS-PAGE in $10 \%$ (w/v) polyacrylamide gels as previously reported (Howard et al., 1981).

\section{Table 1. Ureaplasma strains}

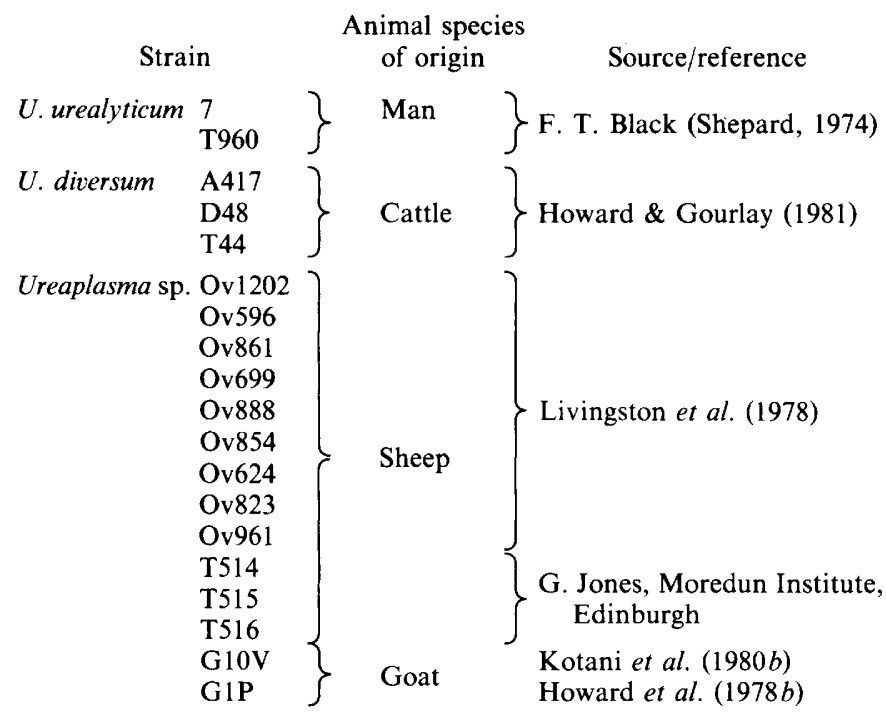




\section{RESULTS}

\section{Comparison of ovine-caprine ureaplasma strains by immunofluorescence}

Thirteen ureaplasma strains were examined for their reactions with three antisera. Two strains, Ov1202 (an isolate from Texas) and T514 (an isolate from Scotland) appeared to be similar and could be grouped together. Of the remaining eleven strains, six reacted with antisera to T515, four reacted with antisera to T515 and Ov624 while one, Ov624, reacted with its homologous antiserum only (Table 2 ).

Comparison, by immunofluorescence and metabolism-inhibition, of selected ovine isolates with $U$. diversum and $U$. urealyticum

Three ovine strains that appeared to typify the serological types of caprine-ovine ureaplasmas were compared with strains representing the three serogroups of $U$. diversum and two strains representing $U$. urealyticum serotypes 1 and 8 . Homologous titres are shown in Table 3 . All heterologous titres were $<20$.

After treatment of colonies with Triton X-100, all of the strains Ov1202, T515, A417, D48, T44, 7, and T960 fluoresced with all seven antisera. Titres ranged from 20 to 640, homologous titres were unchanged by Triton X-100 treatment. The immunofluorescence titres did not enable strains from the same species of animal to be grouped together. Also, no fluorescence was observed with bovine antiserum against Mycoplasma arginini. Thus, the reaction following Triton X-100 treatment appears restricted to the genus Ureaplasma and is not non-specific.

The same strains were also compared by the metabolism-inhibition test (Table 3). No crossreactions were found between ovine, bovine and human strains. However, differences between the titres of the antisera in the metabolism-inhibition and immunofluorescence test were apparent. In the metabolism-inhibition test the homologous titres against the two human isolates were $\geqslant 20480$, against the ovine strains they were 2560-5120 and against the bovine strains, 40-80. This was not due to the gnotobiotic status of the animals in which antisera were prepared as a further antiserum prepared against strain A417 in a conventionally reared calf also had very little antibody detectable by metabolism inhibition. Furthermore, rabbit antiserum to strain A417 had a homologous titre of $\geqslant 20480$ and a titre of 320 and 40 to strains D48 and T44, respectively in the metabolism-inhibition test. Thus, no inherent failure of bovine strains to react in this test was evident.

Table 2. Serological characterization of ovine-caprine ureaplasma strains by immunofluorescence

Titres were taken as the reciprocal of the highest dilution that produced fluorescence with fluoresceincoupled rabbit anti-bovine serum (see Methods).

\begin{tabular}{lccc} 
Strain used & \multicolumn{3}{c}{ Titre with antiserum to: } \\
\cline { 2 - 4 } as antigen & Ov1202 & T515 & Ov624 \\
Ov1202 & 1280 & $<20$ & $<20$ \\
T514 & 160 & $<20$ & $<20$ \\
T515 & $<20$ & 320 & $<20$ \\
T516 & $<20$ & 80 & $<20$ \\
Ov861 & $<20$ & 80 & $<20$ \\
Ov888 & $<20$ & 40 & $<20$ \\
Ov961 & $<20$ & 40 & $<20$ \\
G1P & $<20$ & 80 & $<20$ \\
Ov854 & $<20$ & 80 & 20 \\
Ov699 & $<20$ & 80 & 80 \\
Ov596 & $<20$ & 80 & 40 \\
Ov823 & $<20$ & 160 & 80 \\
Ov624 & $<20$ & $<20$ & 160
\end{tabular}


Table 3. Comparison of selected ovine, bovine and human ureaplasmas by immunofluorescence and metabolism-inhibition

Immunofluorescence and metabolism-inhibition assays were done as described in Methods.

Strain used as antigen

Ov1202 Ureaplasma sp. (sheep)

T515 Ureaplasma sp. (sheep)

Ov624 Ureaplasma sp. (sheep)

A417 U. diversum (cattle)

D48 U. diversum (cattle)

T44 U. diversum (cattle)

$7 \quad$ U. urealyticum (man)

T960 U. urealyticum (man)
Titre with homologous antiserum* by

$\begin{array}{cc}\text { Immunofluorescence } & \text { Metabolism-inhibition } \\ 1280 & 5120 \\ 320 & 5120 \\ 160 & 2560 \\ 160 & 40 \\ 320 & 40 \\ 320 & 80 \\ 1280 & \geqslant 20480 \\ 1280 & \geqslant 20480\end{array}$

* The titre with all seven heterologous antisera for all strains was $<20$ in both tests

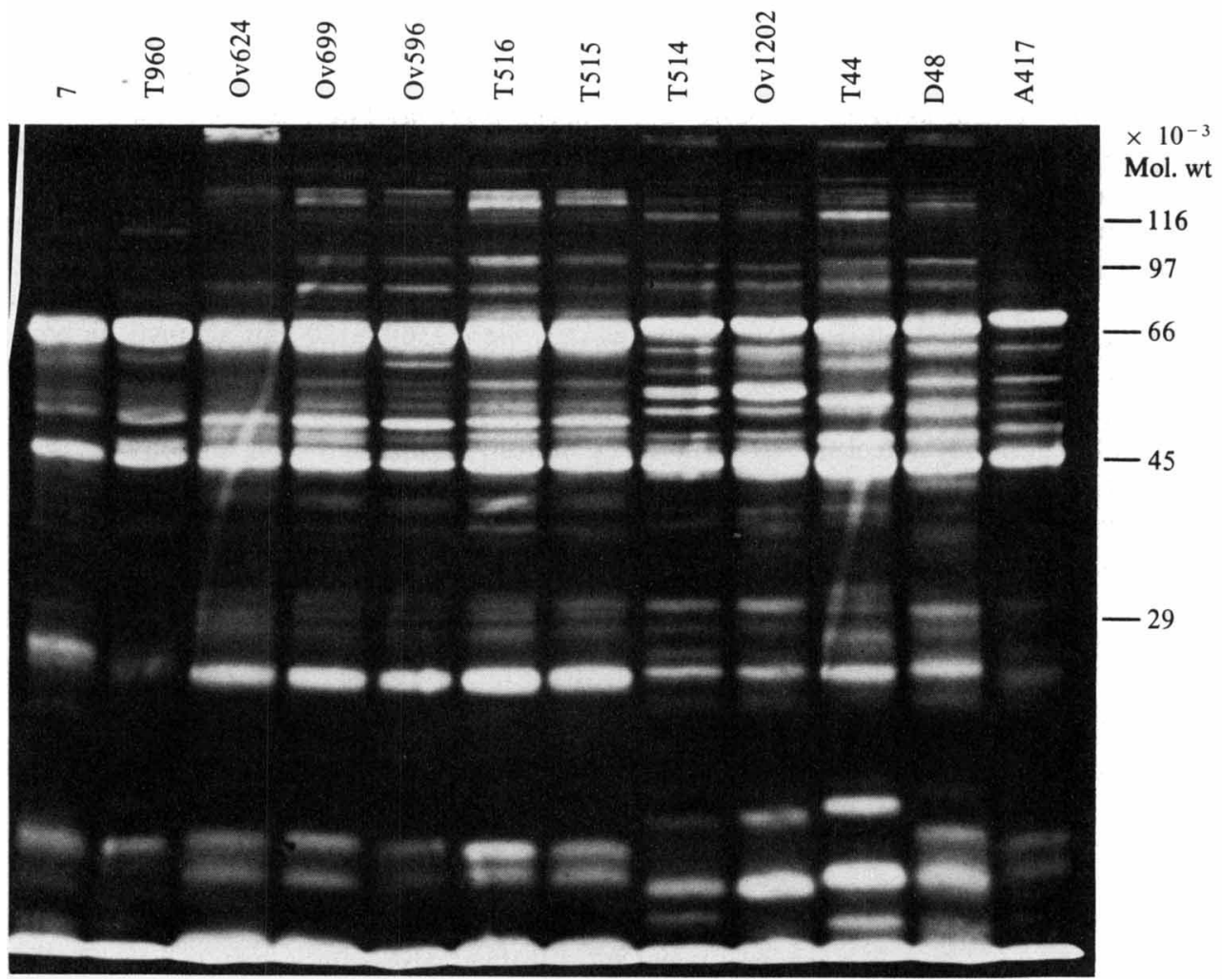

Fig. 1. Analysis of whole-cell lysates of ureaplasmas, grown in the presence of ${ }^{35} \mathrm{~S}$ methionine, by SDSPAGE. Strains 7 and T960 are two U. urealyticum (i.e. human) strains: Ov624, Ov629, Ov596, T516 and T515 comprise a group of similar ovine strains; strains T514 and Ov1202 comprise a second group of ovine strains; strains T44, D48 and A417 represent the three types of $U$. diversum (bovine strains). Molecular weights are from Sigma kit MW-SDS-200.

Comparison of ovine-caprine strains with $U$. urealyticum and $U$. diversum by analysis of polypeptides by $P A G E$

The polypeptides of strains Ov624, Ov699, Ov596, T516, and T515 appeared similar when compared on polyacrylamide gels but distinct from ovine strains Ov1202 and T514, whose polypeptides appeared similar (Fig. 1). In another comparison, ovine strain Ov861 and caprine 
strains G10V and G1P were also found to have polypeptides that appeared similar to strains T516, T515 and Ov596 but distinct from Ov1202.

The polypeptides of the ovine strains were distinct from those of the two selected $U$. urealyticum strains 7 and T960. They were also different from strains T44, D48 and A417, representing the three groups of $U$. diversum.

\section{DISCUSSION}

The ureaplasmas from sheep and goats can be regarded as comprising two serological groups not related to the two species of origin but based on immunofluorescence with antisera prepared in calves. All but two ovine-caprine strains constituted a single large group that reacted with antisera to strains T515 and/or Ov624. The two strains Ov1202 and T514 formed a second distinct group. The large group could be subdivided into three, i.e. those strains that reacted with antisera to either strain T515 or Ov624 and those that reacted with both. Polypeptide analysis also indicated that the ovine-caprine strains could be classified into two groups. One consisted of strains Ov1202 and T514 and the other of the remaining ovine-caprine strains. Thus, the polypeptide analysis confirms that strains should be grouped in the manner indicated by the serological results. These observations are in agreement with those of Kotani et al. (1980 b) who used rabbit antisera. They are also analogous to the findings of three clusters of bovine ureaplasmas. With both the ovine-caprine and bovine ureaplasmas these clusters are not entirely homogeneous, strains within them being distinguishable by rabbit antisera and other methods, e.g. the complement-mediated mycoplasmacidal test (Livingston et al., 1978; Howard et al., 1978a).

The ovine-caprine isolates were serologically distinct from U. urealyticum strains 7 and T960 (serotypes 1 and 8) which were selected as representatives of the two groups within this species. The polypeptides were also distinct. These findings, together with previous observations that the $\mathrm{G}+\mathrm{C}$ contents of ovine and caprine strains were distinct from the range of values for $U$. urealyticum (Howard et al., 1978b), indicates that these isolates should not be classified within this species.

No serological relationship, using the potentially less discriminating bovine antisera, was established between the bovine strains representing $U$. diversum types $\mathrm{A}, \mathrm{B}$ or $\mathrm{C}$ and the ovinecaprine strains. The polypeptides of the larger group of ovine-caprine strains, represented by strains T515 and Ov624, also distinguished these strains from $U$. diversum types A, B and C. However, although the polypeptide pattern observed for strains Ov1202 and T514 was not the same as those obtained for $U$. diversum, they appeared to possess some similar-sized polypeptides and the overall impression was that these strains might more closely resemble $U$. diversum than other ovine-caprine isolates. These observations, together with the previous finding that the $\mathrm{G}+\mathrm{C}$ contents of the DNA from ovine-caprine strains were similar to those of $U$. diversum strains (Howard et al., 1978 b) mean that it is not possible to propose that the ovinecaprine ureaplasmas should be regarded as a separate species. Possibly they represent additional sub-group(s) of $U$. diversum and further tests, for example DNA homology studies, should resolve this.

Previously, it was suggested that bovine antisera were less discriminating, for bovine ureaplasmas, than antisera prepared in rabbits (Howard \& Gourlay, 1981) and in order to make a full comparison of the ovine-caprine, bovine and human strains it could be argued that antisera should be made in cattle, sheep, goats and man. Alternatively, as cattle, sheep and goats have an immune system with many common features that is distinct from that of man then it may be that antisera prepared in any of these ruminants might produce similar results.

Calves produced low levels of metabolism-inhibiting antibodies to bovine ureaplasmas, following subcutaneous injections of antigen in oil adjuvant. This is in contrast to the high levels produced against the two $U$. urealyticum strains and, to a lesser extent, against the ovine-caprine strains. These low metabolism inhibition titres against bovine isolates may be related to ureaplasma pathogenicity and host specificity. Cole \& Ward (1973) reported that Mycoplasma arthritidis generated a poor metabolism-inhibiting antibody response in rats and mice compared 
to other species of mycoplasmas in these animals or to the response generated by $M$. arthritidis in other animal species. It was suggested that this might be important in the pathogenicity of this mycoplasma and a similar argument could apply to the bovine ureaplasmas.

We thank C. W. Livingston (U.S.A.), M. Ogata (Japan), G. Jones (Scotland) and F. T. Black (Denmark) for providing strains and J. Eynon, M. Martin and M. Stephens for technical assistance.

\section{REFERENCES}

Christiansen, C., Black, F. T. \& Freundt, E. A. (1981). Hybridization experiments with deoxyribonucleic acid from Ureaplasma urealyticum serovars I to VIII. International Journal of Systematic Bacteriology 31, 259-262.

COLE, B. C. \& WARD, J. R. (1973). Detection and characterization of defective mycoplasmacidal antibody produced by rodents against Mycoplasma arthritidis. Infection \& Immunity 8, 199-207.

Howard, C. J. \& Gourlay, R. N. (1981). Identification of ureaplasmas from cattle using antisera prepared in gnotobiotic calves. Journal of General Microbiology 126, 365-369.

Howard, C. J. \& Gourlay, R. N. (1982). Proposal for a second species within the genus Ureaplasma, Ureaplasma diversum sp. nov. International Journal of Systematic Bacteriology 32, 446-452.

Howard, C. J., Gourlay, R. N., Garwes, D. J., Pocock, D. H. \& Collins, J. (1974). Base composition of deoxyribonucleic acid from bovine $\mathrm{T}$ mycoplasmas. International Journal of Systematic Bacteriology 24, 373-374.

Howard, C. J., Gourlay, R. N. \& Collins, J. (1975). Serological comparison between twenty-five bovine ureaplasma (T-mycoplasma) strains by immunofluorescence. International Journal of Systematic Bacteriology 25, 155-159.

Howard, C. J., Gourlay, R. N. \& Collins, J. $(1978 a)$. Serological studies with bovine ureaplasmas (T-mycoplasmas). International Journal of Systematic Bacteriology 28, 473-477.

Howard, C. J., Pocock, D. H. \& Gourlay, R. N. $(1978 b)$. Base composition of deoxyribonucleic acid from ureaplasmas isolated from various animal species. International Journal of Systematic Bacteriology 28, 599-601.

Howard, C. J., Pocock, D. H. \& Gourlay, R. N. (1981). Polyacrylamide gel electrophoretic comparison of the polypeptides from ureaplasmas isolated from cattle and humans. International Journal of Systematic Bacteriology 31, 128-130.

Kotani, H. \& Ogata, M. (1979). Isolation and serological grouping of ureaplasmas from dogs. Japanese Journal of Veterinary Science 41, 639-646.

Kotani, H., Harasawa, R., Yamamoto, K. \& Ogata, M. $(1980 a)$. Serological studies with feline ureaplasmas. Microbiology \& Immunology 24, 83-86.

Kotani, H., Nagatomo, H. \& Ogata, M. (1980b). Isolation and serological comparison of ureaplasmas from goats and sheep. Japanese Journal of Veterinary Science 42, 31-40.

Livingston, C. W., Gauer, B. B. \& Shelton, M. (1978). A specific ureaplasma serotype associated with ovine uterine infections. American Journal of Veterinary Research 39, 1699-1701.

Mouches, C., TAYLOR-Robinson, D., STIPKovits, L. \& Bove, J. M. (1981). Comparison of human and animal ureaplasmas by one and two-dimensional protein analysis on polyacrylamide slab gel. Annales de l'Institut Pasteur B 132, 171-196.

Nagatomo, H., Kotani, H., Ogata, M. \& Shimizu, T. (1980). Serological studies of bovine ureaplasmas by agar-gel precipitation test. Japanese Journal of Veterinary Science 42, 9-17.

Ogata, M., Kotani, H. \& Yamamoto, K. (1979). Serological comparison of bovine ureaplasmas. Japanese Journal of Veterinary Science 41, 629-637.

Ogata, M., Kotani, H., Koshimizu, K. \& MagaribuCHI, T. (1981). Isolation and serological characterization of ureaplasmas from nonhuman primates. Japanese Journal of Veterinary Science 43, 521-529.

Purcell, R. H., TAYlor-Robinson, D., Wong, D. \& Chanock, R. M. (1966). Color test for the measurement of antibody to T-strain mycoplasmas. Journal of Bacteriology 92, 6-12.

Robertson, J. A. \& Stemke, G. W. (1982). Expanded serotyping scheme for Ureaplasma urealyticum strains isolated from humans. Journal of Clinical Microbiology 15, 873-878.

Rosendal, S. \& BLACK, F. T. (1972). Direct and indirect immunofluorescence of unfixed and fixed mycoplasma colonies. Acta pathologica et microbiologica scandinavia B 80, 615-622.

Shepard, M. C., Lunceford, C. D., Ford, D. K., Purcell, R. H., TAYloR-Robinson, D., Razin, S. \& BLACK, F. T. (1974). Ureaplasma urealyticum gen. nov., sp. nov.: proposed nomenclature for the human $\mathrm{T}$ (T-strain) mycoplasmas. International Journal of Systematic Bacteriology 24, 160-171.

Stemke, G. W. \& Robertson, J. A. (1981). Modified colony indirect epifluorescence test for serotyping Ureaplasma urealyticum and an adaption to detect common antigenic specificity. Journal of Clinical Microbiology 14, 582-584.

Taylor-Robinson, D., Haig, D. A. \& Williams, M. H. (1967). Bovine T-strain mycoplasma. Annals of the New York Academy of Sciences 143, 517-518. 